\title{
Expression and clinical significance of angiotensin II type 1 receptor in human hepatocellular carcinoma
}

\author{
YUN-FEI DUAN $^{1^{*}}$, XIAO-DONG LI $^{2 *}$, FENG ZHU ${ }^{3}$ and FENG ZHANG ${ }^{1}$ \\ ${ }^{1}$ Department of Liver Transplantation, The First Affiliated Hospital of Nanjing Medical University, Nanjing, Jiangsu 210029; \\ Departments of ${ }^{2}$ Oncology and ${ }^{3}$ Hepatobiliary Surgery, The Third Affiliated Hospital of Soochow University, \\ Changzhou, Jiangsu 213003, P.R. China
}

Received July 21, 2013; Accepted November 7, 2013

DOI: $10.3892 /$ etm.2013.1411

\begin{abstract}
This study aimed to investigate the expression of angiotensin II type 1 receptor (AT-1R) mRNA and the AT-1R protein in human primary hepatocellular carcinoma (PHC), and to attempt to elucidate their association with pathological and clinical characteristics. Fresh tumor and normal liver tissues were obtained from 44 patients with PHC following hepatectomies. AT-1R mRNA levels were quantitatively analyzed by quantitative polymerase chain reaction (qPCR) while the protein levels were assessed by immunohistochemistry. The expression levels of AT-1R were observed in hepatocellular carcinoma tissues and normal liver tissues. The level of AT-1R protein expression in normal liver tissues was higher compared with that in PHC tissues $(\mathrm{P}=0.0033)$. The AT-1R mRNA levels were higher in patients with negative hepatitis $B$ virus surface antigen (HBsAg), normal $\alpha$-fetoprotein (AFP) levels and high tumor differentiation, compared with those in patients with positive HBsAg $(\mathrm{P}=0.0005)$, upregulated AFP levels $(\mathrm{P}=0.0008)$ and poor tumor differentiation $(\mathrm{P}=0.0290)$. No significant correlation was identified between the expression levels of AT-1R mRNA and general characteristics such as gender, age, cirrhotic nodules, tumor size, tumor encapsulation, tumor number, carcinoma embolus, tumor metastasis or tumor recurrence. Downregulated levels of AT-1R mRNA and AT-1R protein may indicate a poor prognosis for patients with PHC.
\end{abstract}

\section{Introduction}

Primary hepatocellular carcinoma (PHC), a prevalent cancer, is the third leading cause of cancer related mortality $(1,2)$.

Correspondence to: Professor Feng Zhang, Department of Liver Transplantation, The First Affiliated Hospital of Nanjing Medical University, Nanjing, Jiangsu 210029, P.R. China

E-mail: zhangf@njmu.edu.cn

*Contributed equally

Key words: angiotensin II type 1 receptor, hepatocellular carcinoma, differentiation
Furthermore, the incidence of PHC is increasing in many countries and regions, particularly in China (2). Additionally, only $20 \%$ of patients are eligible for curative surgery, with limited therapeutic options for those who are ineligible. Failure to achieve a timely diagnosis, in addition to the limited efficacy of palliative treatments, contributes to the poor prognosis for PHC patients. Furthermore, PHC remains a highly lethal disease due to the recurrence of metastasis, thereby leading to poor patient prognosis (3).

Due to the scarcity of efficacious testing methods, the identification of novel PHC biomarkers is necessary. To date, several studies have focused on tests that are capable of detecting and monitoring PHC, including tests for the ratio of glycosylated $\alpha$-fetoprotein (AFP; L3 fraction) to total AFP, and prothrombin induced by vitamin $\mathrm{K}$ absence II (PIVKA II), $\alpha$-fucosidase and HSP-70 levels (4). However, the specificity and sensitivity of these serological markers are low and have been demonstrated to be inadequate and impractical for the purposes of PHC screening, even when they are combined (2).

Angiotensin II (AT-II) is a major peptide hormone of the renin-angiotensin system (RAS), which is crucial for maintaining cardiovascular homeostasis and mediating diverse physiological functions such as cell growth, differentiation and apoptosis (5). The majority of AT-II actions are mediated by its two sub-receptors, which are the AT-II type 1 receptor (AT-1R) and the AT-II type 2 receptor (AT-2R) (6). These two subunits control the effects of AT-II on various organs $(5,7)$, while AT-2R is less common than AT-1R and has been observed in fetal cells (8).

Previous studies have revealed AT-II to have major functions in several aspects of neoplastic diseases, which indicate an anti-neoplastic action for AT-II by binding to activated AT-1R (9). Activation of the AT-1R associated with tumor development may be via various pathways. AT-1R has the potential to stimulate tumor growth factors, which results in the suppression of immune function (10). AT-1R assists vascular endothelial growth factor (VEGF) to promote tumor vessel growth. Furthermore, AT-1R is capable of mediating inflammation by stimulating various inflammatory factors including interleukin $1 \beta$, tumor necrosis factor- $\alpha$, plasminogen activator inhibitor-1 and adrenomedullins $(11,12)$. These effects cause enduring tumor vessel growth, tumor invasion and metastasis, and immunosuppression, thereby leading to the development 
of tumors. Kawamata et al (13) transformed non-invasive esophageal cancer cells into AT-1R overexpressed invasive esophageal cancer cells, and suggested that nine inflammationrelated genes in the cells were altered, indicating that AT-1R promoted tumor growth via inflammation-inducing factors.

Numerous studies have reported that AT-1R overexpression is potentially associated with various malignancies such as non-small cell lung cancer (14), gastric cancer $(15,16)$, breast cancer (17,18), ovarian cancer (19), bladder cancer $(20,21)$, pancreatic cancer $(22,23)$ and prostate cancer (24-27). However, currently there is limited literature regarding AT-1R expression in patients with $\mathrm{PHC}$ and the results are frequently contradictory. Di et al (28) demonstrated that AT-1R was overexpressed in human hepatocellular carcinoma tissues by using immunohistochemistry, and thus concluded it was a marker reflecting the degree of malignancy of the hepatocellular carcinoma. However, Wu et al (29) concluded that the levels of AT-1Rs in normal tissues were markedly higher compared with those in hepatocellular carcinoma tissues by immunohistochemistry in a murine xenograft hepatocellular cancer model. Nevertheless, the two studies used traditional semi-quantitative methods, which leads to a certain degree of subjectivity and possible inaccuracy. Additionally, subgroups of PHC were not mentioned.

This study aimed to determine AT-1R mRNA and AT-1R protein levels in PHC tissues, elucidate their association with the clinicopathological characteristics of PHC and confirm the clinical value of AT-1R as a biomarker for PHC in clinical diagnosis.

\section{Patients and methods}

Patient enrollment and tissue samples. In total, 44 patients with PHC were enrolled between January 2007 and June 2013 in the Department of Hepatobiliary Surgery, The Third Affiliated Hospital of Soochow University (Changzhou, China). All diagnoses were verified pathologically. Clinical data were obtained by retrospective chart review. Survival was determined from the date of the initial surgery. Follow-up was available for all patients. The survival period

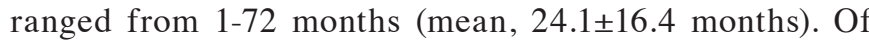
the 44 patients, 36 were male and 8 were female. The ages ranged between 28-78 years with an average age of 52 years. All enrolled patients were treated with radical surgery for PHC and received no other treatments. A section of tumor tissue $0.5 \times 0.5 \times 0.5 \mathrm{~cm}$ was obtained from each patient immediately after the surgery. Additionally a section of normal liver tissue, $0.5 \times 0.5 \times 0.5 \mathrm{~cm}$ and $>5 \mathrm{~cm}$ away from the tumor margin was obtained. All tissue samples were fixed in $10 \%$ formalin, embedded in paraffin, and routinely stained with hematoxylin and eosin. Specimens were assessed blindly and independently by two pathologists. In case of interobserver disagreement, final decisions were achieved by general consensus. The cancer grading was determined by histology according to Edmondson's criteria (30). Edmondson's grade I-II was designated low-grade PHC and Edmondson grade III-IV was designated high-grade PHC. All enrolled patients provided written consent. The protocol was approved by the institutional ethics review board at Soochow University. This study complies with the principles
Table I. Baseline patient characteristics $(n=44)$.

\begin{tabular}{|c|c|c|}
\hline Clinicopathologic factors & No. patients & $\%$ \\
\hline \multicolumn{3}{|l|}{ Gender } \\
\hline Female & 36 & 81.8 \\
\hline Male & 8 & 18.2 \\
\hline \multicolumn{3}{|l|}{ Age (years) } \\
\hline Average & 52 & \\
\hline Range & $28-78$ & \\
\hline \multicolumn{3}{|c|}{ Edmondson's pathological grade } \\
\hline I-II & 24 & 54.5 \\
\hline III-IV & 20 & 45.5 \\
\hline \multicolumn{3}{|l|}{ HBsAg infection } \\
\hline Positive & 40 & 90.9 \\
\hline Negative & 4 & 9.1 \\
\hline \multicolumn{3}{|l|}{$\operatorname{AFP}(\mathrm{ng} / \mathrm{ml})$} \\
\hline$\leq 20$ & 6 & 13.6 \\
\hline$>20$ & 38 & 86.4 \\
\hline \multicolumn{3}{|l|}{ Hepatocirrhotic nodule $(\mathrm{cm})$} \\
\hline$\leq 3$ & 34 & 77.3 \\
\hline$>3$ & 10 & 22.7 \\
\hline \multicolumn{3}{|l|}{ Tumor size (cm) } \\
\hline$\leq 5$ & 8 & 18.2 \\
\hline$>5$ & 36 & 81.9 \\
\hline \multicolumn{3}{|l|}{ Tumor encapsulation } \\
\hline Yes & 26 & 59.1 \\
\hline No & 18 & 40.9 \\
\hline \multicolumn{3}{|l|}{ Tumor number } \\
\hline Single & 34 & 77.3 \\
\hline Multiple & 10 & 22.7 \\
\hline \multicolumn{3}{|l|}{ Cancerous embolus } \\
\hline Yes & 14 & 31.8 \\
\hline No & 30 & 68.2 \\
\hline \multicolumn{3}{|l|}{ Recurrence } \\
\hline Yes & 10 & 22.7 \\
\hline No & 34 & 77.3 \\
\hline
\end{tabular}

HBsAg, hepatitis B virus surface antigen; AFP, $\alpha$-fetoprotein.

of the Declaration of Helsinki and Good Clinical Practice Guidelines.

Quantitative polymerase chain reaction ( $q P C R)$. Unless indicated otherwise, all reagents for qPCR were purchased from Fermentas-China Inc. (Shenzhen, China). Total RNA was extracted from the tumor and normal tissues using an extraction reagent (Shennengbocai Inc., Shanghai, China) according to the manufacturer's instructions. RNA samples were stored at $-70^{\circ} \mathrm{C}$ until required. PCR was performed using a RevertAid ${ }^{\mathrm{TM}}$ First Strand cDNA Synthesis kit with PCR primers for synaptophysin designed by TaqMan ${ }^{\circledR}$ Gene Expression Assays (Invitrogen, Carlsbad, CA, USA). RNA (3 $\mu \mathrm{g})$ was reverse transcribed using the First Strand cDNA Synthesis kit with 


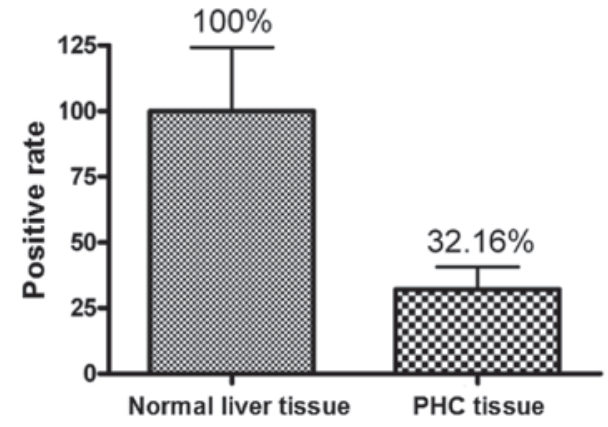

Figure 1. Comparison of angiotensin II type 1 receptor (AT-1R) mRNA expression in normal liver tissues and primary hepatocellular carcinoma (PHC) tissues. Relative expression rates of AT-1R mRNA expression in normal tissues and tumor tissues were 100 and $32.16 \%$, respectively $(\mathrm{P}=0.0033)$.

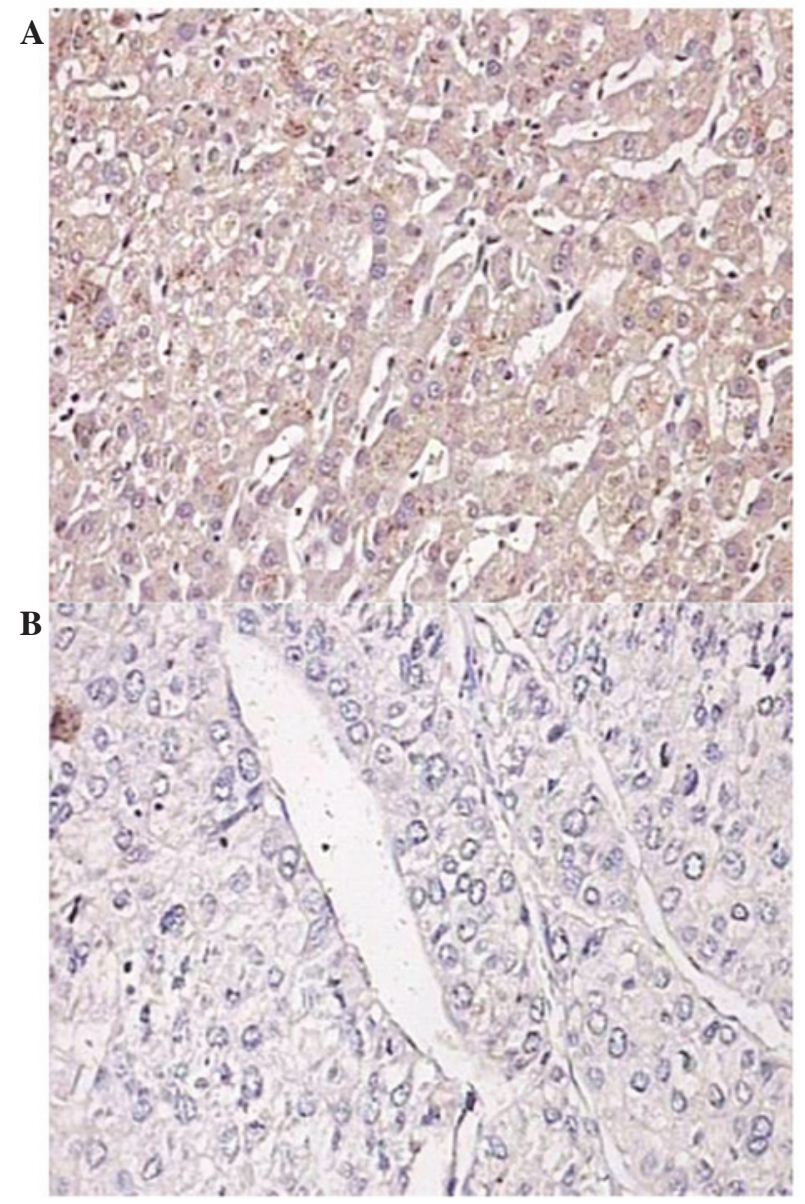

Figure 2. Expression of angiotensin II type 1 receptor (AT-1R) protein (magnification, $\mathrm{x} 200$ ). (A) AT-1R is mainly expressed in the cytoplasm presenting as brown granules in normal tissue. (B) AT-1R granules are observed in PHC tissue.

$0.5 \mu \mathrm{g}$ oligo $(\mathrm{dT})_{16}$ according to the manufacturer's instructions. The reaction mixture was incubated at $70^{\circ} \mathrm{C}$ for $5 \mathrm{~min}$, and subsequently at $0^{\circ} \mathrm{C}$ for $30 \mathrm{sec}$. The cDNA concentration was determined by spectrophotometer. Glyceraldehyde 3-phosphate dehydrogenase (GAPDH) was used as an internal control. Specific primers for AT-1R were synthesized as follows: forwards, 5'-AGACAGATGACGGCTGCTCG-3'; reverse, 5'-AACAATCTGGAACTCTCATCTCCTG-3'.

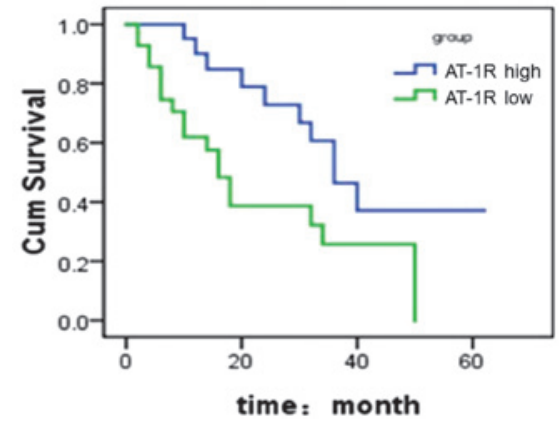

Figure 3. Comparison of overall survival rate of patients with high and low expression of angiotensin II type 1 receptor (AT-1R) mRNA in hepatocellular carcinoma specimens. Cum, cumulative.

Specific primers for GAPDH were synthesized as follows: forwards, 5'-GGAAGGTGAAGGTCGGAGTC-3'; reverse, 5'-CGTTCTCAGCCTTGACGGT-3'. The cycling conditions were as follows: initial denaturation at $95^{\circ} \mathrm{C}$ for $3 \mathrm{~min}$, followed by 40 cycles at $95^{\circ} \mathrm{C}$ for $15 \mathrm{sec}$, and a final extension for $45 \mathrm{sec}$ at $60^{\circ} \mathrm{C}$. The relative level of gene expression was evaluated using $2^{-\Delta \Delta \mathrm{Ct}}$.

Immunohistochemistry. All reagents for immunohistochemistry were obtained from R\&D systems, Inc. (Minneapolis, MN, USA). Tissue sections (5 $\mu \mathrm{m})$ were deparaffinized in xylene, rehydrated in an ethanol series and subsequently treated for $30 \mathrm{~min}$ with $0.3 \%$ hydrogen peroxide, washed with phosphate-buffered saline (PBS) and unmasked in a citrate antigen unmasking solution for $20 \mathrm{~min}$ at $120^{\circ} \mathrm{C}$. The sections were incubated with primary antibodies [rabbit anti-human polyclonal antibody to AT-1R (1/50)] for $1 \mathrm{~h}$ at room temperature. The bound primary antibodies were detected by adding secondary antibodies (peroxidase labeled goat anti-human IgG) and avidin/biotin/horseradish peroxidase complex (Dako, Carpinteria, CA, USA) for $30 \mathrm{~min}$ at room temperature. The sections were visualized using solid diaminobenzidine diluted with PBS, counterstained with hematoxylin and mounted. Breast cancer tissue was used as the positive control. Three independent investigators assessed the positivity of AT-1R semiquantitatively without prior knowledge of the clinical study. The intensity of cytoplasmic staining was defined as negative (stained cells, $<20 \%$ ) or positive (stained cells, $\geq 20 \%$ ).

Statistical analysis. Data were analyzed using GraphPad Prism 5 (GraphPad Software Inc., San Diego, CA, USA). The differences in AT-1R mRNA levels between PHC tissues and normal tissues were compared using the Wilcoxon test. The differences in AT-1R mRNA among various subgroups of PHC were analyzed using the non-pairing t-test. $\mathrm{P}<0.05$ was considered to indicate a statistically significant difference.

\section{Results}

Baseline patient characteristics. Baseline patient characteristics, including gender, age, pathological grade, HBS infection status, tumor size and number as well as recurrence status are shown in Table I. 
Table II. Correlation between the clinicopathological factors of PHC patients and AT-1R levels in tumor tissues ( $\mathrm{n}=44$ ).

\begin{tabular}{|c|c|c|c|c|}
\hline Clinicopathological factor & Cases & $\begin{array}{c}\text { AT-1R/GAPDH } \\
(\text { Mean } \pm \text { SD })\end{array}$ & t-value & P-value \\
\hline \multicolumn{5}{|l|}{ Gender } \\
\hline Male & 36 & $0.3199 \pm 0.4104$ & \multirow[t]{2}{*}{0.0407} & \multirow[t]{2}{*}{0.9680} \\
\hline Female & 8 & $0.3292 \pm 0.4140$ & & \\
\hline \multicolumn{5}{|l|}{ Age (years) } \\
\hline$\leq 50$ & 18 & $0.3341 \pm 0.2943$ & \multirow[t]{2}{*}{0.1183} & \multirow[t]{2}{*}{0.9070} \\
\hline$>50$ & 26 & $0.3130 \pm 0.4728$ & & \\
\hline \multicolumn{5}{|l|}{ HBsAg } \\
\hline Negative & 4 & $1.1660 \pm 0.8565$ & \multirow[t]{2}{*}{4.1670} & \multirow[t]{2}{*}{$0.0005^{\mathrm{a}}$} \\
\hline Positive & 40 & $0.2371 \pm 0.2378$ & & \\
\hline \multicolumn{5}{|l|}{$\operatorname{AFP}(\mathrm{ng} / \mathrm{ml})$} \\
\hline$\leq 20$ & 6 & $0.9730 \pm 0.7784$ & \multirow[t]{2}{*}{3.9340} & \multirow[t]{2}{*}{$0.0008^{\mathrm{a}}$} \\
\hline$>20$ & 38 & $0.2188 \pm 0.1961$ & & \\
\hline \multicolumn{5}{|l|}{ Hepatocirrhotic nodule $(\mathrm{cm})$} \\
\hline$\leq 3$ & 34 & $0.3426 \pm 0.4142$ & \multirow[t]{2}{*}{0.4431} & \multirow[t]{2}{*}{0.6624} \\
\hline$>3$ & 10 & $0.2504 \pm 0.3873$ & & \\
\hline \multicolumn{5}{|l|}{ Tumor size $(\mathrm{cm})$} \\
\hline$\leq 5$ & 8 & $0.1225 \pm 0.0714$ & \multirow[t]{2}{*}{1.1030} & \multirow[t]{2}{*}{0.2829} \\
\hline$>5$ & 36 & $0.3659 \pm 0.4317$ & & \\
\hline \multicolumn{5}{|l|}{ Tumor encapsulation } \\
\hline No & 18 & $0.1999 \pm 0.1491$ & \multirow[t]{2}{*}{1.1960} & \multirow[t]{2}{*}{0.2456} \\
\hline Yes & 26 & $0.4059 \pm 0.4979$ & & \\
\hline \multicolumn{5}{|c|}{ Edmondson's pathological grade } \\
\hline I-II & 24 & $0.4881 \pm 0.4841$ & \multirow[t]{2}{*}{2.3520} & \multirow[t]{2}{*}{$0.0290^{\mathrm{a}}$} \\
\hline III-IV & 20 & $0.1218 \pm 0.0867$ & & \\
\hline \multicolumn{5}{|l|}{ Tumor number } \\
\hline Single & 34 & $0.3323 \pm 0.4257$ & \multirow[t]{2}{*}{0.2250} & \multirow[t]{2}{*}{0.8243} \\
\hline Multiple & 10 & $0.2853 \pm 0.3429$ & & \\
\hline \multicolumn{5}{|l|}{ Cancerous embolus } \\
\hline No & 30 & $0.3840 \pm 0.4636$ & \multirow[t]{2}{*}{1.0730} & \multirow[t]{2}{*}{0.2962} \\
\hline Yes & 14 & $0.1878 \pm 0.1759$ & & \\
\hline Recurrence & & & & \\
\hline No & 34 & $0.3413 \pm 0.4370$ & 0.4163 & 0.6816 \\
\hline Yes & 10 & $0.2546 \pm 0.2710$ & & \\
\hline
\end{tabular}

${ }^{a} \mathrm{P}<0.05$. PHC, primary hepatocellular carcinoma; AT-1R, angiotensin II type 1 receptor; GAPDH, glyceraldehyde 3-phosphate dehydrogenase; HBsAg, hepatitis B virus surface antigen; AFP, $\alpha$-fetoprotein.

AT-1R mRNA expression. AT-1R mRNA and GAPDH mRNA were expressed in all hepatocellular carcinoma tissues and normal liver tissues. In 40 cases (90.9\%), the AT-1R mRNA expression level in normal tissues was higher compared with that in the tumor tissues, and the opposite was observed for the other four cases. The difference was considered to be statistically significant $(\mathrm{P}=0.0033)$. The relative expression rates of AT-1R mRNA in normal tissues and in tumor tissues were 100 and $32.16 \%$, respectively (Fig. 1).

$A T-1 R$ protein expression. The majority of the AT-1R expression was detected in the cytoplasm. The number of positively stained cells and the staining density were markedly higher in the normal tissues compared with those in the tumor tissues (Fig. 2).

Correlation between AT-1R mRNA expression and clinicopathological factors. The AT-1R mRNA expression levels in cases which were positive for HBsAg infection (40/44) were markedly higher compared with those in cases which were negative for HBsAg infection (4/44) $(\mathrm{P}=0.0005)$. The AT-1R mRNA expression levels in cases with normal AFP levels (6/44) were markedly higher compared with those in cases with aberrantly increased AFP levels (38/44) $(\mathrm{P}=0.0008)$. The 
AT-1R mRNA expression levels in cases with Edmondson's pathological grade I-II (24/44) were markedly higher compared with that in cases with Edmondson's pathological grade III-IV (20/44) (P=0.0290; Table II).

Notably, the data from the 5-year follow-up demonstrated a correlation between AT-1R mRNA expression level and patient survival rate. In cases with high levels of AT-1R mRNA expression, the 3-year survival rate was $46 \%$, with a median survival time of 35.5 months. However, in cases with low levels of AT-1R mRNA expression, the 3-year survival rate was $26 \%$, with a median survival time of 15.6 months (Fig. 3).

However, no correlation was observed between AT-1R mRNA expression and other clinical features, such as age, gender, tumor number, tumor size, cirrhosis status, tumor encapsulation, cancerous embolus and recurrence (Table II).

\section{Discussion}

PHC represents a paradigm of the correlation between the tumor microenvironment and tumor development (31). It has been demonstrated that controlling the growth of tumor vessels is an important modality for the treatment of PHC.

To date, the function of the VEGF family for generating tumor vessel growth has been relatively well clarified (32). VEGF is crucial in the development of PHC by inducing tumor vessel growth in the early stages, and VEGF levels have been observed to correlate positively with microvessel density (33). However, the mechanism by which VEGF regulates PHC cells growth has not been fully elucidated. Fujiyama et al (34) demonstrated that AT-II promoted the expression of VEGF by endothelial cells.

The results of the present study indicated that the level of AT-1R expression in normal liver tissues was higher than that in tumor tissues, potentially due to that fact that the majority of PHC cases had HBV-related hepatocirrhosis (36/44). This indicates that the upregulation of AT-1R expression is correlated with hepatocyte proliferation. Furthermore, it was observed that the AT-1R mRNA expression level correlated negatively with hepatocyte differentiation. Once PHC formed an invasive cancer, which broke through the basement membrane, AT-1R expression was downregulated. Takeda et al (35) demonstrated that positive rates of AT-1R expression in well-differentiated, moderately differentiated and poorly differentiated squamous cell carcinomas were 81,72 and $0 \%$, respectively, which were consistent with the results of the present study.

De Paepe et al (36) applied immunohistochemistry and in situ hybridization to investigate the expression of AT-1R in various stages of breast cancer, and the results revealed that AT-1R was overexpressed in neoplasms with a relatively low level of malignancy. These results are consistent with those of the present study. De Paepe et al (36) hypothesized that AT-1R was an important mediator for the precursors of breast cancer but not a necessary protein for invasive breast cancer. Similarly, we considered that AT-1R is unnecessary for PHC. Lower expression levels of AT-1R in PHC tissues leave the blood supply for PHC cells unaffected by AT-II, leading to the sustained growth of PHC; this is a difference between PHC and normal vessels.

Notably, the data from the present study demonstrated that patients with higher levels of AT-1R mRNA expression have an improved survival rate, indicating that AT-1R is a novel prognostic factor in hepatic carcinoma.

In conclusion, AT-1R mRNA is expressed in normal liver tissue and PHC tissue. AT-1R mRNA levels correlate negatively with the degree of malignancy of PHC, which is a potential cause of the increased blood supply in PHC tissues. AT-1R mRNA expression correlates with PHC cell differentiation, but does not correlate with gender, age, hepatocirrhotic nodules, tumor size, tumor number, cancerous embolus, tumor encapsulation or tumor recurrence. These results suggest that AT-1R expression correlates with PHC development, and inhibits AT-1R expression prior to invasive tumor formation, which may prevent PHC from growing progressively. Future studies concerning the correlation between AT-1R and other ligands are warranted.

\section{Acknowledgements}

The authors would like to thank Dr Chun Yang for technical support. This work was funded by grants from the Jiangsu Health International Exchange Supporting Program provided by Xiao-Dong Li.

\section{References}

1. Jemal A, Bray F, Center MM, et al: Global cancer statistics. CA Cancer J Clin 61: 69-90, 2011.

2. Bruix J and Sherman M; American Association for the Study of Liver Diseases: Management of hepatocellular carcinoma: an update. Hepatology 53: 1020-1022, 2011.

3. Bruix J, Boix L, Sala M and Llovet JM: Focus on hepatocellular carcinoma. Cancer Cell 5: 215-219, 2004.

4. Bruix J and Sherman M; Practice Guidelines Committee, American Association for the Study of Liver Diseases: Management of hepatocellular carcinoma. Hepatology 42: 1208-1236, 2005

5. Paul M, Poyan Mehr A and Kreutz R: Physiology of local renin-angiotensin systems. Physiol Rev 86: 747-803, 2006.

6. Wang $\mathrm{CH}, \mathrm{Li} \mathrm{F}$ and Takahashi N: The renin angiotensin system and the metabolic syndrome. Open Hypertens J 3: 1-13, 2010.

7. Tahmasebi M, Barker S, Puddefoot JR and Vinson GP: Localisation of renin-angiotensin system (RAS) components in breast. Br J Cancer 95: 67-74, 2006.

8. Jethon A, Pula B, Piotrowska A, et al: Angiotensin II type 1 receptor (AT-1R) expression correlates with VEGF-A and VEGF-D expression in invasive ductal breast cancer. Pathol Oncol Res 18: 867-873, 2012

9. Deshayes F and Nahmias C: Angiotensin receptors: a new role in cancer? Trends Endocrinol Metab 16: 293-299, 2005.

10. Kobie JJ, Wu RS, Kurt RA, et al: Transforming growth factor beta inhibits the antigen-presenting functions and antitumor activity of dendritic cell vaccines. Cancer Res 63: 1860-1864, 2003.

11. Suzuki Y, Ruiz-Ortega M, Lorenzo O, et al: Inflammation and angiotensin II. Int J Biochem Cell Biol 35: 881-900, 2003.

12. Tsutamoto T, Wada A, Maeda K, et al: Angiotensin II type 1 receptor antagonist decreases plasma levels of tumor necrosis factor alpha, interleukin- 6 and soluble adhesion molecules in patients with chronic heart failure. J Am Coll Cardiol 35: 714-721, 2000.

13. Kawamata H, Furihata T, Omotehara F, et al: Identification of genes differentially expressed in a newly isolated human metastasizing esophageal cancer cell line, T.Tn-AT1, by cDNA microarray. Cancer Sci 94: 699-706, 2003.

14. Wilop S, von Hobe S, Crysandt M, et al: Impact of angiotensin I converting enzyme inhibitors and angiotensin II type 1 receptor blockers on survival in patients with advanced non-small-cell lung cancer undergoing first-line platinum-based chemotherapy. J Cancer Res Clin Oncol 135: 1429-1435, 2009.

15. Huang W, Wu YL, Zhong J, et al: Angiotensin II type 1 receptor antagonist suppress angiogenesis and growth of gastric cancer xenografts. Dig Dis Sci 53: 1206-1210, 2008. 
16. Huang W, Yu LF, Zhong J, et al: Angiotensin II type 1 receptor expression in human gastric cancer and induces MMP2 and MMP9 expression in MKN-28 cells. Dig Dis Sci 53: 163-168, 2008.

17. Inwang ER, Puddefoot JR, Brown CL, et al: Angiotensin II type 1 receptor expression in human breast tissues. Br J Cancer 75: 1279-1283, 1997.

18. Chen X, Meng Q, Zhao Y, et al: Angiotensin II type 1 receptor antagonists inhibit cell proliferation and angiogenesis in breast cancer. Cancer Lett 328: 318-324, 2013.

19. Ino K, Shibata K, Kajiyama H, et al: Angiotensin II type 1 receptor expression in ovarian cancer and its correlation with tumour angiogenesis and patient survival. Br J Cancer 94: 552-560, 2006

20. Tanaka N, Miyajima A, Kosaka T, et al: Acquired platinum resistance enhances tumour angiogenesis through angiotensin II type 1 receptor in bladder cancer. Br J Cancer 105: 1331-1337, 2011.

21. Shirotake S, Miyajima A, Kosaka T, et al: Angiotensin II type 1 receptor expression and microvessel density in human bladder cancer. Urology 77: e19-25, 2011.

22. Ohta T, Amaya K, Yi S, et al: Angiotensin converting enzyme-independent, local angiotensin II-generation in human pancreatic ductal cancer tissues. Int J Oncol 23: 593-598, 2003.

23. Gong Q, Davis M, Chipitsyna G, et al: Blocking angiotensin II type 1 receptor triggers apoptotic cell death in human pancreatic cancer cells. Pancreas 39: 581-594, 2010.

24. Uemura $\mathrm{H}$, Ishiguro $\mathrm{H}$, Nakaigawa $\mathrm{N}$, et al: Angiotensin II receptor blocker shows antiproliferative activity in prostate cancer cells: a possibility of tyrosine kinase inhibitor of growth factor. Mol Cancer Ther 2: 1139-1147, 2003.

25. Guimond MO, Battista MC, Nikjouitavabi F, et al: Expression and role of the angiotensin II AT2 receptor in human prostate tissue: in search of a new therapeutic option for prostate cancer. Prostate 73: 1057-1068, 2013.

26. Hoshino K, Ishiguro H, Teranishi J, et al: Regulation of androgen receptor expression through angiotensin II type 1 receptor in prostate cancer cells. Prostate 71: 964-975, 2011.
27. Kosaka T, Miyajima A, Shirotake S, et al: Phosphorylated Akt up-regulates angiotensin II type-1 receptor expression in castration resistant prostate cancer. Prostate 71: 1510-1517, 2011

28. Di MJ, Wang WX, Lan MY, et al: Expression and significance of angiotensin II typeI receptor in human hepatocellular carcinoma. Medical Journal of Wuhan University 26: 235-237, 2005 (In Chinese).

29. Wu Y, Cahill PA and Sitzmann JV: Decreased angiotensin II receptors mediate decreased vascular response in hepatocellular cancer. Ann Surg 223: 225-231, 1996.

30. Edmondson HA and Steiner PE: Primary carcinoma of the liver: a study of 100 cases among 48,900 necropsies. Cancer 7: 462-503, 1954

31. Capece D, Fischietti M, Verzella D, et al: The inflammatory microenvironment in hepatocellular carcinoma: a pivotal role for tumor-associated macrophages. Biomed Res Int 2013: 187204, 2013.

32. Holash J, Maisonpierre PC, Compton D, et al: Vessel cooption, regression, and growth in tumors mediated by angiopoietins and VEGF. Science 284: 1994-1998, 1999.

33. Li XM, Tang ZY, Qin LX, et al: Serum vascular endothelial growth factor is a predictor of invasion and metastasis in hepatocellular carcinoma. J Exp Clin Cancer Res 18: 511-517, 1999.

34. Fujiyama S, Matsubara H, Nozawa Y, et al: Angiotensin AT(1) and AT(2) receptors differentially regulate angiopoietin-2 and vascular endothelial growth factor expression and angiogenesis by modulating heparin binding-epidermal growth factor (EGF)-mediated EGF receptor transactivation. Circ Res 88: 22-29, 2001.

35. Takeda H and Kondo S: Differences between squamous cell carcinoma and keratoacanthoma in angiotensin type-1 receptor expression. Am J Pathol 158: 1633-1637, 2001.

36. De Paepe B, Verstraeten VL, De Potter CR, et al: Growth stimulatory angiotensin II type-1 receptor is upregulated in breast hyperplasia and in situ carcinoma but not in invasive carcinoma. Histochem Cell Biol 116: 247-254, 2001. 